\title{
Role of Anorectal Manometry in Anal Fissure and Outcome of Tailored Lateral Sphincterotomy in Hypertensive Internal Anal Sphincter: A Modified Minimal Invasive Technique
}

\author{
BESHOY N. NAEEM, M.Sc.; ABDALLAH B. ABDALLAH, M.D.; ALMOATAZ A. EL-TAYEB, M.D. and \\ RAMY A. HASSAN, M.D.
}

The Department of General Surgery, Faculty of Medicine, Assiut University, Assiut, Egypt

\begin{abstract}
Background: CAF is a common benign anorectal problem that substantialy impairs the patient's life. Consequently, a rapid and effective solution is required.1

Aim of Study: To do lateral internal sphincterotomy extending up to the upper end of the fissure (but not to the dentate line) in patients have CAF with hypertonic IAS to keep continence. In case of low RAP, V-Y plasty will be done.

Patients and Methods: Our study was done on 34 patients with CAF divided into 2 groups, group 1 included 28 patients with hypertonic IAS underwent tailored LIS and group 2 included 6 patients with normotonic/ hypotonic IAS underwent V-Y plasty to keep continence from June 2017 till December 2017 in general surgery department ,Assiut university hospital.

Results: In group 1 there is no incontinence or recurrence, complete healing of fissures occurred in $96.4 \%$. Only one patient had unhealing fissures, postoperative complications include bruising occurred in $3.5 \%$ and minor sepsis of sphincterotomy wound in $3.5 \%$, in group 2 there is minor sepsis of the flap in $16.6 \%$.
\end{abstract}

Conclusion: Our study was done on 34 patients with CAF. These patients were divided according to anomanometric study into 2 groups:

- Group 1 included 28 patients with high RAP in whom tailored LIS was done by modified technique which is taiored equal to the length of the fissure which is minimally invasive with good healing rate and no recurrence or incontince postoperative and minor bruising and sepsis of the wound and significant reduction in postoperative RAP.

- Group 2 included 6 patients with normotonic /hypotonic IAS in whom excison of fissures were done and the defect is closed by V-Y plasty with good healing rate and low postoperative sepsis.

So tailored lateral internal sphincterotomy is the effective treatment of CAF with anal hypertonia, safe and not affect continence.

Key Words: Anal fissure-Anorectal manometry - Tailored lateral sphincterotomy.

Correspondence to: Dr. Beshoy N. Naeem, E-Mail: beshoynobar2013@yahoo.com

\section{Introduction}

CAF is a common benign anorectal problem that substantialy impairs the patient's life. Consequently, a rapid and effective solution is required [1] These patients have several anal pressure profiles, but most of them have hypertonic internal anal sphincter with raised resting anal sphincter $[2,3]$ Surgical internal sphincterotomy is recommended as the first therapeutic approach in those with anal hypertonia [1]. It achives permenant reduction of hypertonia with relief of symptoms and is very successful at healing CAF but requires an operation with associated low morbidity [4]. Posterior sphincterotomy has largely been abandoned because of the resultant gutter deformity which may impair anal closure with consequent fecal soiling [s. So, LIS by either open [6] or closed [7] technique is the treatment of choice. There is a possibility of injury of EAS and the anal mucosa as well as the possibility of incomplete sphincterotomy because infiltration of local anesthetic in adrenaline masks its assessment. On the other hand, this technique has the advantages that it avoids an open intra anal wound, the divided IAS is bridged by skin, there is minimal anal wound care, postoperative dilatation is unnecessary and relief from symptoms is almost immediate, with the fissure becoming painless and healing occurs within 3 weeks [8]. In addition, the intigerity of IAS must be assessed preoperatively by anal manometry. If it is already compromised and the RAP is not raised, internal sphincterotomy

\footnotetext{
Abbreviations:

CAF: Chronic anal fissure.

IAS : Internal anal sphincter.

RAP: Resting anal pressure.

EAS: External anal sphincter.

LIS : Lateral internal sphincterotomy.
} 
is contraindicated $[9,10]$ and $\mathrm{V}-\mathrm{Y}$ plasty will be done.

\section{Patients and Methods}

This study was done on 34 patients with chronic anal fissure divided into 2 groups, group 1 included 28 patients with hypertonic internal sphincter underwent tailored lateral sphincterotomy and group 2 included 6 patients with normotonic or hypotonic internal sphincter underwent V-Y plasty and 30 control subjects (age and sex matched) who have no anal complaint to keep continence from June 2017 till December 2017 in General Surgery Department, Assiut University Hospital.

\section{Inclusion criteria:}

All cases of chronic anal fissure.

\section{Exclusion ctiteria:}

- Patients with previous anal operation.

- Patients having ulcerative colitis or Crohns disease.

- Patients with perianal fistula.

- Patients with underlying abcess or fistula.

- Patients with anal stenosis.

- Patients with haemorrhoids

\section{Preparation of patients:}

Patients fast 6 hours and received single enema one hour befor operation. The perianal area was shaved. Each one received antibiotic prophylaxis in the form of metronidazole $500 \mathrm{mg}$ tab tds orally 24 hours before the operation and single dose of second generation cephalosporin (1.5 cefuroxime sodium) before induction of anesthesia.

\section{Technique:}

\section{Group I patients with hypertonic IAS:}

They were underwent modified tailored lateral internal sphincterotomy. The procedure was done in lithotomy position under general or spinal anesthesia according to patient preference and physical fitness. At first examination under anesthesia was carried out then a modified tailored lateral internal sphincterotomy was done as described by Abdallah et al., 2008 [11] through circumferential peri-anal skin landmark about $5 \mathrm{~mm}$ length was done with tip of scalpel along the intershincteric groove in the left later position of the anal verge.

A bivalve rectal speculum was then introduced into the anal canal and opened in the sagittal plane to expose the left lateral wall of the canal and stretch the IAS. The lower edge of the IAS was palpated by the tip by the tip of index finger where its distal third is hypertrophied and presents a distinct palpable band in patient with hypertonic IAS [12]

Tilting of the speculum slightly to the right side of the patient draws the ISA downwards then a skin incision of about $5-7 \mathrm{ml}$ was done in previous skin landmark along the interspincteric groove just lateral to the edge of IAS. The lower end of the wound will grasped with a toothed dissecting foreceps and the IAS was dissected out from the anoderm using dissecting scissor. While the left index finger in anal canal dissecting scissors was introduced into intersphincteric plane dissect0ing the IAS from EAS. Undervision known by its white color or under palpation by the tip of left index finger the lower edge of IAS was grasped by haemostat and the lower part of IAS was withdrawn out of the wound and sphincterotomy was done safely using scissors. The extent of sphincterotomy was done to be more or less equal the length of the fissure that marked on the scissors. Sphincterotomy was assessed by pressure with the tip of left index finger to palpate the groove produced in the IAS at the site of sphincterotomy while the speculum was opened in place and the IAS was stretrched. If the extent was found insufficient further extension of sphincterotomy was done with scissor while the IAS in place until it reached the upper end of the fissure. Some bleeding usually occurred after this step. This was easily controlled by compression with a guaze for 3-5minutes. If there was a bleeding from the wound edge it was controlled by diathermy coagulation. The wound was left open for drainage. However there was a slight ooze of blood from the small external wound but this was arrested postoperatively by tamponad as EAS recovered and contracted around the IAS [10], so we applied $\mathrm{T}$ shaped bandge for a few hours. Sentinel tag anal polyp and markedly fibrotic fissure were excised if present.

After sterilization with povidone iodine $10 \%$ the wound was covered with a flat dressing and secured with a $\mathrm{T}$ bandage.

Group II patient with normotonic or hypotonic IA:

Excision of the fissure accompanying sentinel tag or hypertrophic anal papilla were done and the raw area was closed with V-Y plasty flap.

Follow-up:

Follow-up was done for 6 months for:

- Persistence of the symptoms.

- Local complications (brusing, sepsis, soiling and incontinence). 
- Healing of fissure (anoderm became intact) was assessed by examination of anus in both left lateral and knee chest positions during straining, while the buttocks were separated. If it was found healed, complete healing is assessed by proctoscopic examination.

- RAP after 6 weeks.

- Recurrence after complete healing

- Statistical study it was done by SPSS ver 11 using paired $t$-test to compare the same variable in the same group (paired quantitative data).

\section{Results}

Study included 34 patients, 28 patients with hypertonic IAS and 6 patients with hypotonic or normotonic IAS. Control group included 30 subjects.

According to Anorectal manometric study, patients were divided into two groups: Group I patients with hypertonic IAS.

Twenty eight patients has hypertonic IAS compared with the control group who underwent tailored lateral internal sphincterotomy. There were 10 females and 18 males, the mean age was 40.68 years (ranging from 28 to 52 years) and attended the follow-up for at least six months. The clinical data details are showen in Table (1).

Sentinel tag was found in 13 patients $(46.4 \%)$, anal polyp in 2 patients $(7.1 \%)$ and both in 5 patients (17.9\%). Fissures were excised in 9 patients $(32.1 \%)$.

All patients had significant increase of preoperative RAP (mean $=130.89 \pm 6.61 \mathrm{cmH}_{2} \mathrm{O}$ ) compared with that of controls (mean $=79.64 \pm 7.10$ $\mathrm{cmH}_{2} \mathrm{O}$ ) with $p$-value 0.001 Table (2).

Postoperative progress of patients is outlined in Table (3).Within the first postoperative $24 \mathrm{hs}, 8$ patients $(28.6 \%)$ who underwent sphincterotomy only responded to a single i.m dose of ketorolac tromethamine $30 \mathrm{mg}$ (ketolac, amriya pharmaceutical). The remaining patients, 13 patients $(46.4 \%)$ needed additional dose of nalbuphine $20 \mathrm{mg}$ i.m and 7 patients (25\%) needed further dose of i.m ketorolac tromethamine. Within the first week, pain responded to oral diclofenac 50mg twice daily in 25 patient $(89.3 \%)$ with 2 patients $(7.1 \%)$ needed oral analgesia and topical anesthetic for additional week. One patient $(3.5 \%)$ with unhealed fissure needed application of topical anesthetic (lidocaine hydrochloride jelly 2\%, Xylocaine by Astra Zeneca) after defecation for additional 4 weeks. Twenty five patients $(89.3 \%)$ were comfortable enough to open their bowels normally with laxatives ( 2 Tablets) each consisted of $5 \mathrm{mg}$ bisacodyl and $100 \mathrm{mg}$ dioctyl sodium sulphosuccinate at bed time) after 48 hours of operation. Sepsis of sphincterotomy wound (edges were swollen, red, painful and tender without pus discharge) occurred in one patient (3.6\%) and sites of excised fissures and sentinel tags (there was pain and tenderness with pus discharge from raw surface) in 5 patients $(17.9 \%)$. All infections were minor sepsis and controlled by topical antibiotic (Fusidinic acid 2\% cream). Improvement occur after its extraction. No incontinence to flatus or solid stool occurred.

Fissures healed completely (intact andoderm with complete disappearance of preoperative symptoms) in 24 patients $(85.7 \%)$ with in 4 weeks and the end of 6 th week fissures healed in 27 patients $(96.4 \%)$. The other patient $(3.5 \%)$ with unhealed fissure had had 3 inflammed fissures with edematous anus and sphincterotomy was difficult to be done properly and assessed. Postoperative RAP was $108 \mathrm{cmH}_{2} \mathrm{O}$ indicating insufficient sphincterotomy which was repeated on the right side of the anus and fissures healed within additional 7 weeks.

Postoperative manometric study after 6 weeks of the operation (after getting complete healing) showed that the mean postoperative RAP dropped significantly in 27 patients (mean $=78.09 \pm 6.62 \mathrm{~cm}$ $\mathrm{H} 2 \mathrm{O}$ ) compared with preoperative mean value with $p$-value is 0.001 Table (4).

The Postoperative RAP of patients was within the range of control group but it mean value was significantly lower $(p$-value $=0.003)$.

After follow-up period of 4 to 6 months (mean 5.3 months), no recurrence is reported.

Group II patients with normotonic/hypotonic IAS:

Six patients has normotonic or hypotonic IAS compared with the control group who underwent $\mathrm{V}-\mathrm{Y}$ plasty. There were 4 females and 2 males, the mean age was 41.70 years (ranging from 28 to 52 years) and a attended the follow-up for 2 to 6 months.

Sentinel tag was found in all patients (100\%), anal polyp in 3 patients (33.3\%).

All patients had significant decrease of preoperative RAP (mean $\left.=61.37 \mathrm{cmH}_{2} \mathrm{O}\right)$ compared with that of controls (mean $\left.=79.64 \mathrm{cmH}_{2} \mathrm{O}\right)$ with $p$-value 0.001 Table (6). 
Postoperative progress of patients is minor sepsis of the flap in one patient $(16.6 \%)$ and controlled by topical antibiotic (Fusidinic acid 2\% cream).

Table (1): Clinical data of 28 patients with hypertonic IAS.

\begin{tabular}{lcc}
\hline Patient characteristics & Number & Percentage \\
\hline Mean Age & 28-52 (40.68ys) & \\
Sex: & & \\
$\quad$ Male & 18 & 64.3 \\
Femle & 10 & 35.7 \\
Main symptom: & & \\
Pain & 26 & 92.9 \\
Bleeding & 2 & 7.1 \\
Site of fissure: & & \\
Anterior & 3 & 10.7 \\
Posterior & 19 & 67.9 \\
Anterior and posterior & 4 & 14.3 \\
Multiple & 2 & 7.1 \\
\hline
\end{tabular}

Table (2): Preoperative RAP of patints with hypertonic IAS and controls.

\begin{tabular}{llcc}
\hline RAP & $\begin{array}{c}\text { Rang in } \\
\left(\mathrm{cmH}_{2} \mathrm{O}\right)\end{array}$ & $\begin{array}{c}\text { Mean } \\
\left(\mathrm{cmH}_{2} \mathrm{O}\right)\end{array}$ & $\begin{array}{c}p \text { - } \\
\text { value }\end{array}$ \\
\hline Patient group & $120-151$ & 132.89 & $<0.001$ \\
Control group & $68-91$ & 79.64 & \\
\hline
\end{tabular}

Table (3): Clinical results of sphincterotomy.

\begin{tabular}{lll}
\hline Postoperative Course & No. & Percentage \\
\hline Pain control within 24hs & & \\
with injectable Analgesia: & & \\
$\quad$ Single dose & 13 & 28.6 \\
2 doses & 7 & 25 \\
3 doses & & \\
Response of pain to oral & & \\
analgesia/local Anaesthetic: & 25 & 89.3 \\
$\quad$ Within 1 st week & 2 & 7.1 \\
$\quad$ For 2 weeks & 1 & 3.6 \\
$\quad$ For 6 weeks & 25 & 89.3 \\
Return of bowel function after48hs & & \\
$\quad$ Postoperative complications: & 1 & 3.5 \\
$\quad$ Perianal bruising & 1 & 3.5 \\
$\quad$ Sepsis of sphincterotomy wound & 5 & 17.9 \\
$\quad$ Sepsis at site of excised sentinel tag & 5 & \\
$\quad \&$ fissure & & \\
$\quad$ Incontinence to solid stool/flatus & 0 & \\
Healing of fissures within 6 ws: & & \\
$\quad$ Healed & 27 & 96.4 \\
$\quad$ Unhealed & 1 & 3.6 \\
Recurrence & 0 & \\
\hline
\end{tabular}

Table (4): Pre-and postoperative RAP of patients with hypertonic IAS.

\begin{tabular}{llll}
\hline RAP & $\begin{array}{c}\text { Preop. RAP } \\
\left(\mathrm{cmH}_{2} \mathrm{O}\right)\end{array}$ & $\begin{array}{c}\text { Postop. RAP } \\
\left(\mathrm{cmH}_{2} 0\right)\end{array}$ & $\begin{array}{c}p- \\
\text { value }\end{array}$ \\
\hline Range & $120-151$ & $66-89$ & $<0.001$ \\
Mean & $132.89 \pm 6.61$ & $78.09 \pm 6.62$ & \\
\hline
\end{tabular}

Table (5): Clinical data of 6 patients normotonic or hypotonic IAS.

\begin{tabular}{lcc}
\hline Patient characteristics & Number & Percentage \\
\hline Mean Age & 28-52 (41.70ys) & \\
Sex: & & \\
$\quad$ Male & 2 & 33.3 \\
$\quad$ Femle & 4 & 66.6 \\
Main symptom: & & \\
$\quad$ Pain & 5 & 83.3 \\
$\quad$ Bleeding & 1 & 16.6 \\
Site of fissure: & & \\
$\quad$ Posterior & 6 & 100 \\
\hline
\end{tabular}

Table (6): RAP of patints with normotonic or hypotonic IAS.

\begin{tabular}{llcc}
\hline RAP & $\begin{array}{c}\text { Rang in } \\
\left(\mathrm{cmH}_{2} \mathrm{O}\right)\end{array}$ & $\begin{array}{c}\text { Mean } \\
\left(\mathrm{cmH}_{2} \mathrm{O}\right)\end{array}$ & $\begin{array}{c}p- \\
\text { value }\end{array}$ \\
\hline Patient group & $59-71$ & 61.37 & $<0.001$ \\
Control group & $68-91$ & 79.64 & \\
\hline
\end{tabular}

\section{Discussion}

Our study was done in patients with anal fissure and included 34 patients and 30 control subjects. These patients were divided according to anomanometric study into 2 groups:

- Group I patients with hypertonic IAS (compared with control).

- Group II patient with normotonic or hypotonic IAS (compared with control).

Group 1: Included 28 patients with hypertonic IAS, 18 males (64.3\%) and $10(35.7 \%)$ females with mean age $40.68 \mathrm{ys}$ (range from 28 to $52 \mathrm{ys}$ ). Main complaint of patients is pain in 26 patients $(92.9 \%)$ and bleeding in 2 patients $(7.1 \%)$, site of fissure is 19 posterior $(67.9 \%), 3$ anterior $(10.7 \%)$, 4 comined (14.3\%) and 2 multiple (7.1\%), Sentinel tag was found in 13 patients (46.4\%), anal polyp in 2 patients $(7.1 \%)$ and both in 5 patients $(17.9 \%)$. Fissures were excised in 9 patients $(32.1 \%)$. In 2008, Abdallah Badawy et al., reported pain in $(95.7 \%)$ and bleeding in $(4.3 \%)$, site of fissure is $(72.9 \%)$ posterior, $(8.6 \%)$ anterior, $(12.9 \%)$ combined, (5.7\%) multiple. Sentinel tag was found in (47.1\%), anal polyp in (5.7\%) and both in (18.6\%). Fissures were excised in 18 patients [11]. In another 
study pain was present for more than a month in all the patients, constipation was present in $(75$. $42 \%)$ and bleeding in $(25.42 \%)$, site of fissure was posterior in $(92 \%)$ and anterior in $(8 \%)$ [13]. Jennifer et al reported pain $(100 \%)$, bleeding $(80 \%)$, pruritus ani (39\%), constipation (26\%) with the most common site being posterior $(80 \%)$. The presence of anal tag was reported in $(47 \%)$ patients and hypertrophic papilla was documented in (14\%) [14]. Also there is a study reported that constipation in $(80 \%)$, bleeding in (68.6\%), and pain in (74.7\%) [15] However, these variation in the symptomatology due to racial variations and the number of patients in each group.

Our patients in group 1 had significantly high $\mathrm{RAP}$ range from $120-150 \mathrm{cmH}_{2} \mathrm{O}$ (mean $132.89 \pm$ $7.1 \mathrm{cmH}_{2} \mathrm{O}$ ) compared with control subjects range from $68-91 \mathrm{cmH}_{2} \mathrm{O}$ (mean 79.64 $\pm 7.1 \mathrm{cmH}_{2} \mathrm{O}$ ). Increase RAP was also recorded by other studies and ranging from $\left(85.47 \pm 4.48 \mathrm{cmH}_{2} \mathrm{O}\right.$ to $132.89 \pm 7.1 \mathrm{~cm}$ $\mathrm{H} 2 \mathrm{O})[11,16]$.

Tailored lateral internal sphincterotomy was done by modified technique which is taiored equal to the length of the fissure to not affect the continence.This technique is decribed firstly by Abdallah Badawy et al., [11]. It is done safetly under vision without any danger to the andoderm or EAS through a small extra anal incision. So, it is minimally invasive technique and has advantages of both open and closed techniques at the same time.

In our study, $89.3 \%$ of patients were comfortable enough to open their bowels normally after 48 hours of the operation with laxative. Local complications related to sphincterotomy incision were minimal. Within the ${ }^{1 \mathrm{st}}$ week pain respond to oral analgesia in $89.3 \%$ of patients with $7.1 \%$ needed oral analgesia and topical anaesthetic for additional week. Abdallah, et al., reported that $90 \%$ of patients respond to oral analgesia Within the ${ }^{1 \text { st }}$ week and $8.6 \%$ for 2 weeks and $1.4 \%$ for 6 weeks needed oral analgesia and topical anaesthetic for additional week [11]. In another study, after 6 months (94.06\%) patients remained free from symptoms and were fully satisfied with the results of surgery, while $5.93 \%$ patients had mild pain. They were symptom free after the second procedure [13].

In our study, postoperative complications include bruising occurred in $3.5 \%$ (one patient) and minor sepsis of sphincterotomy wound in $3.5 \%$ (one patient) which was easily controlled by topical antibiotics, Sepsis at site of excised sentinel tag and fissure in 5 patients (17.9\%). In 2008, Abdallah Badawy et al., reported bruising in $1,4 \%$ and minor sepsis of sphincterotomy wound in $1.4 \%$ [11]. Sarabjit, et al reported early post operative complications included mild soiling in $8.47 \%$ patients [13] In another study, $7.5 \%$ patients had wound infection, $10.3 \%$ patients were in open method and $4.2 \%$ patient was in closed method which is treated by antibiotics [17]. In 2017, Ravikumar et al recorded two patients had wound infection during the first follow-up visit, while two patients presented with infection during the second visit and settled without any need for surgical intervention [18].

In our study no incontinence was reported which is the same result reported by Abdallah, et al., and Abdulwahid, [11,15]. In other studies it was reported that incontinence of flatus in $5.93 \%$ patients by Sarabjit, et al., [13] and $8.3 \%$ patients in closed method had temporary incontinence to flatus which was controlled within 1 week, $3.4 \%$ patient in open method had temporary incontinence to flatus which was controlled within 1 week by Harshad et al., [17], 4\% patients developed minor incontinence postoperatively by Jennifer et al., 2015 [14], 4.2\% patients are reported incontinence during the first follow-up visit by Ravikumar, et al., 2017 [18] However, in our study we do tailored sphincterotomy and never reach dentate line so no incontinence in our study.

In our study, Complete healing of fissures occurred in $85.7 \%$ within 4 weeks and by the end of 6 weeks fissures healed in $96.4 \%$ (27 patients). only one patient had unhealing fissures due to insufficient sphincterotomy which was less than the length of the fissures. In other studies it was reported healing rate was $97.2 \%$ by the end of 6 weeks [11], $98 \%$ of patients [14], $100 \%$ of patients had completely healed fissures at the end of 4 weeks [19], patient satisfaction (98.4\%) was high and complete healing was seen at 4 weeks [15], fissure healed completely in $88.7 \%$ of patients within 4 weeks. It healed by 8 weeks in another 6 patients $(8.5 \%)$ [18].

In our study no recurrence of fissure occurred. However our follow-up is short 4 to 6 months (mean mean 5.3 months) and until that study completed no recurrence reported. This was the same result reported by Harshad et al., within 6 months follow-up [17]. In other studies reported two recurrence by Abdallah Badawy et al., with follow-up mean (15.8 months) [11] and 3 patient had recurrence by Abdulwahid, 2017 [15]

In our study compared with preoperative RAP, there is significant reduction in postoperative RAP (mean $=78.09 \pm 6.62 \mathrm{cmH}_{2} \mathrm{O}, p-0.001$ ) which was 
close to those of control group ( $p=0.003$ ). Decrease RAP after internal sphincterotomy was also recorded by other studies and ranging from $(59.55 \pm 3.50$ to $72.5 \pm 6.6 \mathrm{mmHg}$ ) $[11,16]$

Group 2: Included six Six patients has normotonic/hypotonic IAS $\left(61.37 \mathrm{cmH}_{2} \mathrm{O}\right)$ compared with the control group $\left(79.64 \mathrm{cmH}_{2} \mathrm{O}\right)$ with $p$-value 0.001 . Who underwent V-Y plasty. There were 4 females $(66.7 \%)$ and 2 males (33.3\%), the mean age was 41.70 years (ranging from 28 to 52 years) and a attended the follow-up for 2 to 6 month.

Postoperative progress of patients is minor sepsis of the flap in one patient $(16.6 \%)$ and controlled by topical antibiotic (Fusidinic acid 2\% cream).

\section{Conflicts of interest:}

No conflict of interest has been declared.

\section{References}

1- ARRYO A., PEREZ-VECENTE F., SERRANOCANDELA F., SANCHEZ A., PEREZ-VECENTE F.M.T and CALPAN R.: Treatment of chronic anal fissure. Cir. Esp., 78: 68-74, 2005.

2- NUGENT K.P.: Benign anal disease. Rec. Ad. Surg., 25: 147-60, 2002

3- BROVE A., BALZANO A., PERROTTI P., ANTROPOLI C., LOMBARDI G. and PUCCIANI F.: Differenent anal pressure profiles in patient with anal fissure. Tech. Coloproctol., 8: 151-6, 2004.

4- LIRATOZPOULOUS N., EFREMIDOU E.L., PAPAGEORGIOU M. S., KOUKLAKIS G., MOSCHOS J., MANOLAS K.J., et al.: Lateral subcutaneous internal sphincterotomy in the treatment of chronic anal fissure: Our experience. J. Gastrointestin. Liver. Dis., 15: 143-7, 2006.

5- NYAM DCNK, WILSON R.G., STEWART R.J., FAROUK R. and BARTOLO D.C.: Island advancement flaps in the management of anal fissure. Br. J. Surg., 82: 32628, 1995.

6- PARKS A.G.: The management of fissure in ano. Hospital Medicine, 1: 737-8, 1967.

7- NOTARAS M.J.: Later subcutaneous sphincterotomy for anal fissure a new technique. Proceedings of the Royal Society of Medicine, 62: 713, 1969.
8- NOTARAS: Lateral subcutaneous internal sphincterotomy for anal fissure. Surgery of the colon, Rectum and Anus. Rob and Smiths operative surgery. Edited by L.P. Fielding and Goldberg, 2: 871-79, 1993.

9- NUGENT K.P.: Benign anal disease. Rec. Ad. Surg., 25: 147-60, 2002

10- KENEFICK N.J., GEE A.S. and DURDEY: Treatment of resistant anal fissure with advancement anoplasty. Colorectal. Dis., 4: 663-6, 2002.

11-ABDALLAH BADAWY, ALAA RADWAN, MOHAMED KORANY and MOHAMED EL-YAMANY.: Tailored lateral internal sphincterotomy in management of chronic anal fissure with hypertonic internal anal sphincter. A modified minimal invasive technique and its clinical data and manometric outcome. Egyptian Journal of Surgery, Vol., 27, No. 2, April, 2008

12- GARIA - GRANERO E., MUNOZ-FORNER E., MINGUEZ M., BALLESTER C., GARCIA-BOTELLOS and LLEDO S.: Treatment of chronic anal fissure. Cir. Esp., Vol., 78, pages 24-7, 2005.

13- SARABJIT SINGH, ARUN TAYAL, HARBANT SINGH and VINEET KAUR: Surgical Management of Chronic Anal Fissure: Evaluation of Left Lateral Internal Sphincterotomy (LLIS) JIMSA, April-June Vol., 24 No. 2, 2011.

14- JENNIFER LIANG, M.B.Ch.B. and JAMES M. Church, M.B.Ch.B.: Lateral internal sphincterotomy for surgically recurrent chronic anal fissure The American Journal of Surgery, 210: 715-719, 2015.

15-ABDULWAHID M. SALIH: Chronic anal fissures: Open lateral internal sphincterotomy result; acase series study. Annals of Medicine and Surgery, 15: 56e58, 2017.

16- FARID M., EL NAKEEB A., YOUSSEF M., et al.: Idiopathic hypertensive anal canal: A place of internal sphincterotomy. J. Gastrointest. Surg. Jun., 11m 2009.

17- HARSHAD S.H. ANKARLAL PATEL, JAGDISH CHAVDA, JAYESH PARIKH and NEHAL NAIK: Study of Operated Patients of Lateral Internal Anal Sphincterotomy for Chronic Anal Fissure. Journal of Clinical and Diagnostic Research. Dec., Vol. 7 (12): 2863-2865, 2013.

18-RAVIKUMAR M., TARUN JACOB S.B. and SUMONTH K.: Lateral Anal Sphincterotomy for Chronic Anal Fissures A Comparison of Outcomes and Complications under Local Anaesthesia Versus Spinal Anaesthesia. Journal of Clinical and Diagnostic Research. Jan., Vol. 11 (1): PC08PC12, 2017.

19- GIRIDHAR C.M., PREETHITHA B.K. and SESHAGIRI R.: A Comparative Study of Lateral Sphincterotomy and 2\% Diltiazem Gel Local Application in the Treatment of Chronic Fissure in Ano. Journal of Clinical and Diagnostic Research. Oct., Vol. 8 (10): NC01-NC02, 2014. 


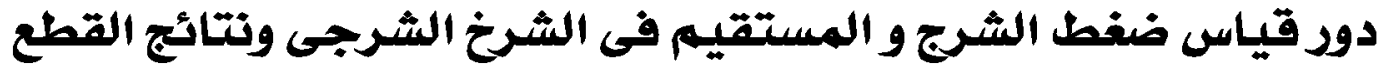

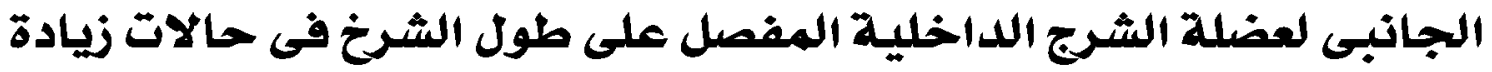

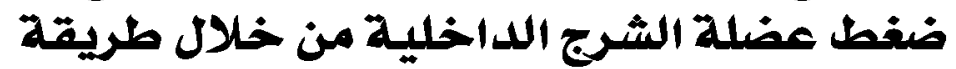

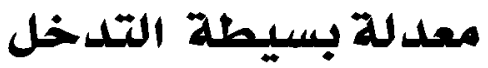

المقدمة: الشرخ الشرجى المزمن يعتبر من الأمراض الشرجية الحميدة المشهودة التى تعيق حياة المريض وهناك أنواع من الشرخ

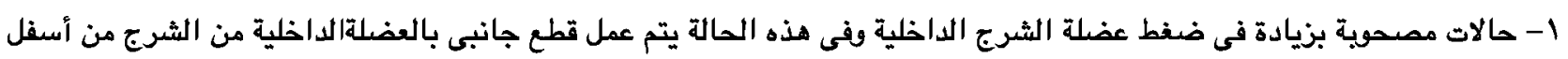

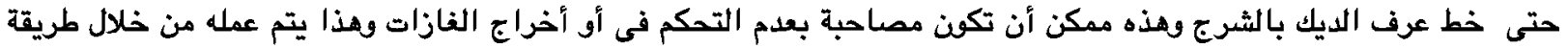
مفتوحة أو طريقة مغلقة. r- حالات مصحوية بضعف في العضلة أو ضغط العضلة عادى وهنا يتم عمل أستئصال الشرخ وعمل v-y plasty. نتائج الرسالة: تم أجراء هذه الدراسة على مرضى الشرخ الشرجى وتم أستخدام جهاز قياس ضغط الشرج لجميع المرضى وهم

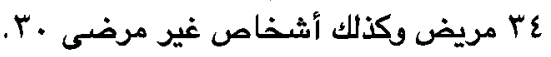

$$
\text { والمرضى قتسموا حسب الضغط الشرجى أثاء راحة الثرج إلى مجموعتين: }
$$

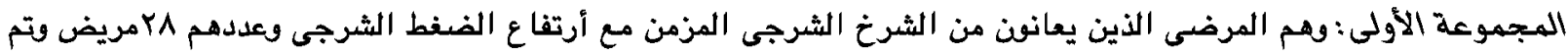

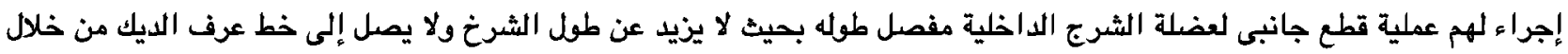

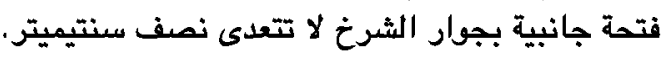

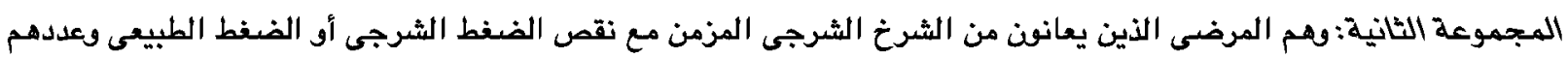

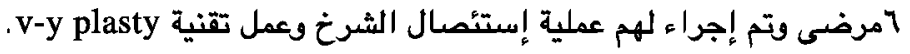

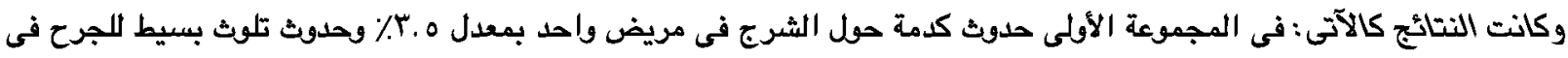

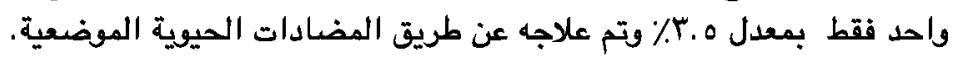

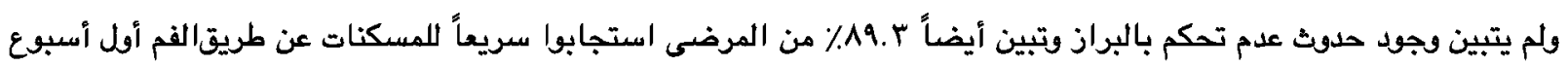

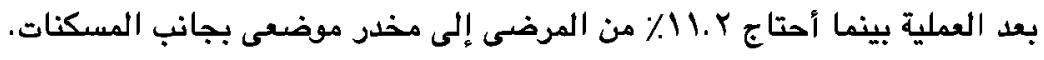

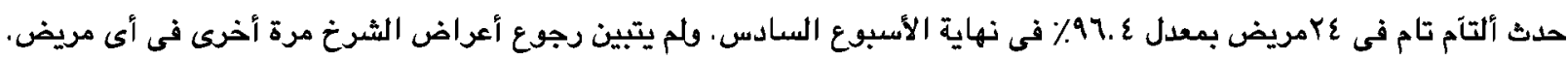
وتبين وجود أنخفاض ملحوظ فى الضغط الشرجى الداخلى بعد العملية مقارنة بالضغط الشرجي الأنى العالى قبل العملية. وفى المجموعة الثانية حدث تلوث بسيط للجرح في واحد فقط بمعل 7.7. .7 وتم علاجه بالمضادات الحيوية. 